\title{
Experimental study and Theoretical analysis on the influence for diverse boiler load to SCR denitrification system
}

\author{
M.T. Cheng \& J. Zhong \& Y. J. Liao \\ Electric Power Science Research Institute of Guangdong Power Grid Co., Ltd., Guangzhou, Guangdong, \\ China
}

J. H. Fan \&Z. Y. Gao

School of Energy and power Engineering, North China Electric power University, Baoding, Hebei, China

\begin{abstract}
This study investigates the performance of SCR catalysts which has been analyzed with a theoretical method from the operation data on the SCR device of a $600 \mathrm{MW}$ unit, and then performance experiments have been done under the high load-600MW\&the low load-320MW. The results show that compared to the NOX distribution at SCR outlet under the 600MW, the 320MW's has become more uneven with the relative standard deviation vk being quite large; Compared to the results through theoretical analysis, the denitrification efficiency measured at field test on the $320 \mathrm{MW}$ is relatively lower than that under $600 \mathrm{MW}$ when $\mathrm{NH} 3 / \mathrm{NO}$ ratio stays constant, the reason of which mainly lies in the obvious change of flue gas flow field at SCR inlet, distributing in an opposite trend to that under 600MW. Improvement and optimization of rectifying device at denitrification inlet flue is recommended to realize uniform flow field, thus in addition to the improvement of NOX distribution uniformity at denitrification outlet and reduction of ammonia escaping rate, the denitrification efficiency is increased, hopefully providing guidance on the economical operation of SCR denitrification system .
\end{abstract}

KEYWORD: load; SCR; relative standard deviation of vk; non-uniform flow field; denitration efficiency

\section{INTRODUCTION}

Nitrogen Oxide (NOx), as one of the major pollutants emissions of coal-fired power plant boile, has serious harm to human health and ecological environment, which has aroused people's attention. As the environmental protection department of $\mathrm{NOx}$ controlling emissions increasingly strictly, flue gas denitration technology is widely applied in coalfired power plant. The selective catalytic reduction (SCR) technology, due to it's a high denitration efficiency and mature technology, is the most widely used in domestic coal-fired power stations with the flue gas denitration technology.

Although the flue flow field characteristics on SCR denitration system took into account in the design phase, denitration entrance of flow field distribution changes as the boiler load is changing with grid needs real-time, whose negative effect on $\mathrm{NH}_{3} / \mathrm{NO}$ ratio raises the amount of ammonia escape and the problem of air preheater block-ing. Therefore, the denitration performance experiments have been conducted on the SCR device of a 600MW unit in a power plant under the high load (600 MW) and low load (320 MW), which the experiment content including flue gas velo-city and composition distribution at SCR import and export, and then analysed the result of the experiment combined with the theory method, which could provide a guidance for SCR denitration system.

\section{RESEARCH OBJECT AND FIELD EXPERI- MENT}

\subsection{Research object}

The SCR reactor arranged between the boiler economizer and air preheater in a $600 \mathrm{MW}$ unit, $99.6 \%$ purity of liquid ammonia as the denitration reductant,was selected for the study.

The denitration device has two reactors and each one was catalyst layout with 2 layers and 1 reserve layer designed. Besides, cellular catalyst adopted as the catalyst, which the main parameters are shown in table 1, and the entrance design values of the flue gas denitration system are shown in table 2 .

Table 1. The main parameters of catalyst.

\begin{tabular}{|c|c|c|c|c|}
\hline \multirow{3}{*}{$\begin{array}{l}\text { operating } \\
\text { temperature }\end{array}$} & \multicolumn{2}{|c|}{ Design temperature } & \multirow{2}{*}{$\begin{array}{l}{ }^{\circ} \mathrm{C} \\
{ }^{\circ} \mathrm{C}\end{array}$} & \multirow{2}{*}{$\begin{array}{l}320 \\
420\end{array}$} \\
\hline & $\begin{array}{l}\text { Maximum } \\
\text { temperature }\end{array}$ & running & & \\
\hline & $\begin{array}{l}\text { minimum } \\
\text { temper-ature }\end{array}$ & running & ${ }^{\circ} \mathrm{C}$ & 300 \\
\hline \multirow{2}{*}{\multicolumn{2}{|c|}{$\begin{array}{l}\text { denitration efficiency } \\
\text { ammonia escap }\end{array}$}} & & $\%$ & $>80$ \\
\hline & & & $(\mu \mathrm{L} / \mathrm{L})$ & $<3$ \\
\hline & & $\%$ & $<1$ \\
\hline \multicolumn{3}{|c|}{ pressure loss of catalyst } & $\mathrm{Pa}$ & $<1100$ \\
\hline \multicolumn{3}{|c|}{ catalyst Chemical life } & $\mathrm{h}$ & 24000 \\
\hline \multicolumn{3}{|c|}{ catalyst mechanical life } & year & 10 \\
\hline
\end{tabular}


Table 2. The design on the parameters of the Inlet flue gain the denitrification system.

$\begin{array}{ccc}\begin{array}{c}\text { parameter } \\ \text { concentration of fly ash }\end{array} & \text { unit } & \text { data } \\ \mathrm{NOx} & \mathrm{mg} / \mathrm{m} 3 & 400 \text { in design } \\ \mathrm{SO}_{2} & \mathrm{mg} / \mathrm{m} 3 & 1500 \\ \mathrm{SO}_{3} & \mathrm{mg} / \mathrm{m} 3 & 18\end{array}$

\subsection{The experiment method}

For the study of research object, the performance experiments have been carried out respectively under high and low load. And the experiments was conducted only on the side of A reactor denitration unde the working condition of $600 \mathrm{MW}$ and 320 MW due to the two sides of reactor has similar laws, which the specific experiment train of thought is:At fist, the flue gas velocity and composition distribution at SCR import and export was tested, and then analysed the results of the experiment combined with the theory method, which could provide a guidance for SCR denitration system.

\section{FIELD EXPERIMENT RESULTS AND ANAL- YSIS}

\subsection{Calculation and analysis of denitrification efficiency}

In the denitrification reactor, the main contractor reaction of Ammonia and NOx under $\mathrm{O} 2$ atmos-phere:

$$
\begin{aligned}
& 4 \mathrm{NO}+4 \mathrm{NH}_{3}+\mathrm{O}_{2} \rightarrow 4 \mathrm{~N}_{2}+6 \mathrm{H}_{2} \mathrm{O} \\
& 2 \mathrm{NO}_{2}+4 \mathrm{NH}_{3}+\mathrm{O}_{2} \rightarrow 3 \mathrm{~N}_{2}+6 \mathrm{H}_{2} \mathrm{O}
\end{aligned}
$$

Reaction in the absence of $\mathrm{O}_{2}$ is:

$6 \mathrm{NO}+4 \mathrm{NH}_{3} \rightarrow 5 \mathrm{~N}_{2}+6 \mathrm{H}_{2} \mathrm{O}$

In the coal-fired boiler SCR reactor, flue gas contains a certain amount of oxygen, NOx is given priority to with NO, therefore in the SCR reaction (1) is the main reaction to NO reduction. In this article the reaction (1) are mainly discussed. Combination law of uz, taking type (5) as the reaction (1) reaction rate equation:

$$
-\frac{\mathrm{d} C_{N O}}{\mathrm{~d} \tau}=k C_{N O}^{n} C_{N H 3}^{n} C_{O_{2}}^{m} \quad(\text { where } \mathrm{n}>0)
$$

$k=A e^{-\frac{E}{R T}}$

Where $\mathrm{C}_{\mathrm{NO}} 、 \mathrm{C}_{\mathrm{NH}} 3 、 \mathrm{CO}_{2}$ as the concentration of $\mathrm{NO} 、 \mathrm{NH}_{3}$ and $\mathrm{O}_{2}$ respectively; $\tau$ as time constant; $\mathrm{n} 、 \mathrm{~m}$ as reaction order; $k$ as apparent rate constant of the reaction type (5); $E$ as apparent activation energy of reaction rate for reaction type (5); $R$ as gas constant; $\mathrm{T}$ as the reaction temperature. If the concentration of $\mathrm{NH}_{3}$ and $\mathrm{NO}$ at $\mathrm{SCR}$ inlet is defined as $\alpha$, the simplified formula of (1) is (5) that will be obtained when ammonia nitrogen ratio is 1 as the con- sumption of $\mathrm{O}_{2}$ in the reaction process can be considered as constant, from which the integral equation (8)of NO concentration in the reactor can be gained similarly.

$$
\begin{aligned}
& -\frac{\mathrm{d} C_{N O}}{\mathrm{~d} \tau}=k C_{N O}^{n} C_{N H 3}^{n} \\
& \int_{C_{N O}^{\prime} O}^{C_{N O}} \frac{\mathrm{d} C_{N O}}{C_{N O}^{2 n}}=\int_{O}^{\tau}-k \mathrm{~d} \tau
\end{aligned}
$$

And the denitrification efficiency formula(9) will be got with the Formula (8) integrated under the $\alpha$ as 1:

$$
\begin{aligned}
\eta & =1-\frac{C_{N O}}{C_{N O, i}} \\
& =\left\{\begin{array}{lc}
1-e^{-k \tau}, & n=\frac{1}{2} \\
1-\frac{1}{k \tau C_{N O, i}+1}, & n=1 \\
1-(2 n-1) \sqrt{\frac{1}{(2 n-1) C_{N O, i}^{2 n-1} k \tau+1}}, n>0 \text { 且 } n \neq \frac{1}{2}, n \neq 1
\end{array}\right.
\end{aligned}
$$

The formula (9) is obtained under the $\alpha$ aslat SCR inlet. Besides, when the $\alpha \neq 1$, the reaction rate in the reactor will be gained as the formula (10) according to formula (7):

$$
-\frac{\mathrm{d} C_{N O}}{\mathrm{~d} \tau}=k C_{N O}^{n}\left[\alpha C_{N O, i}-\left(C_{N O, i}-C_{N O}\right)\right]^{n}
$$

Considering the accurate reaction order is uneasy to ascertain as the reaction (1) includs more elementary reactions, 1 is used as the reaction order $n$ to undertake a qualitative analysis, and the denitrification efficiency formula(11) will be obtained with the Formula (10) integrated:

$$
\eta_{N O}=1-\frac{C_{N O}}{C_{N O, i}}=1-\frac{\alpha-1}{e^{k(\alpha-1) C_{N O, i} \tau}-1}
$$

According to the reactor running datas from the unit under $600 \mathrm{MW}$ load including $\mathrm{CNO}$ that NO concentration at SCR inlet, ammonia nitrogen ratio $\alpha$, denitration efficiency Correspondingly, when the $\alpha=1 \& \alpha=0.84$, the denitration efficiency is respectively $90 \%$ and $82.1 \%$ with the $\mathrm{CNO}=287 \mathrm{mg} / \mathrm{m} 3$, then by type (10) and (12) can be calculated under the condition of the corresponding values of $k \tau$, finally can be calculated by the formula under different alpha denitration efficiency curve as shown in Fig. 1. As you can see, the denitration efficiency is increased with the increase of alpha reactor, that is to say, $\mathrm{CNO}$ at the reactor outlet is necessarily decline under the condition of fixed reactor inlet $\mathrm{NO}$ concentration.

Flue gas temperature at the reactor inlet is basically consistent when Boiler load is relatively stable at a certain value. Therefore, the reactor reaction rate constant $\mathrm{k}$ is the same. According to the type(7), the $\mathrm{k}$ value can be calculated, the $\mathrm{E}$ could be obtained by drawn the curve from the measure data in the la- 
boratory test, which can the relationship between reaction time and denitration efficiency as is shown in Fig.2.

According to the shown in Fig. 2, different time $\tau$ on the denitration effect is different when the unit in a stable working load, but the overall trend is the denitration efficiency increased with the increase of reaction time increase.

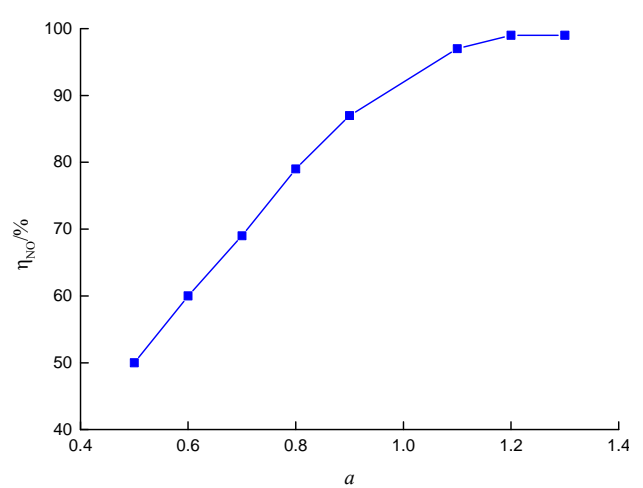

Fig.1 Effect of $\alpha$ on the efficiency of denitrification

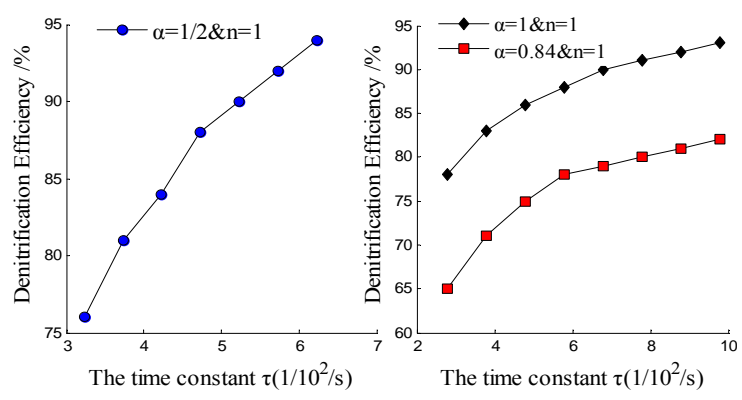

Fig.2 The effect of inlet $\mathrm{NO}_{\mathrm{X}}$ concentration distribution of the $\mathrm{SCR}$ reactor on denitration efficiency

Similarly according to type(16), the curve of relationship between $\mathrm{CNO}$ and denitration efficiency could be obtained with average values of $k \tau$ and NO concentrations and ammonia nitrogen ratio $\alpha$ of reactor A under $600 \mathrm{MW}$ load, as shown in Fig.3, when the $k \tau$ value and ammonia nitrogen ratio $\alpha$ are certain, the higher NO concentration at the reactor inlet is, the higher the denitration efficiency also is . However, both in the pilot experiment and field experiment, the measured denitration efficiency increases with the NO concentration falling, which could be due to the high NO concentration, and NO contact with the surface of the catalyst opportunity is limited, causing part NO molecules could not react with $\mathrm{NH} 3$ on the catalyst and escape directly.

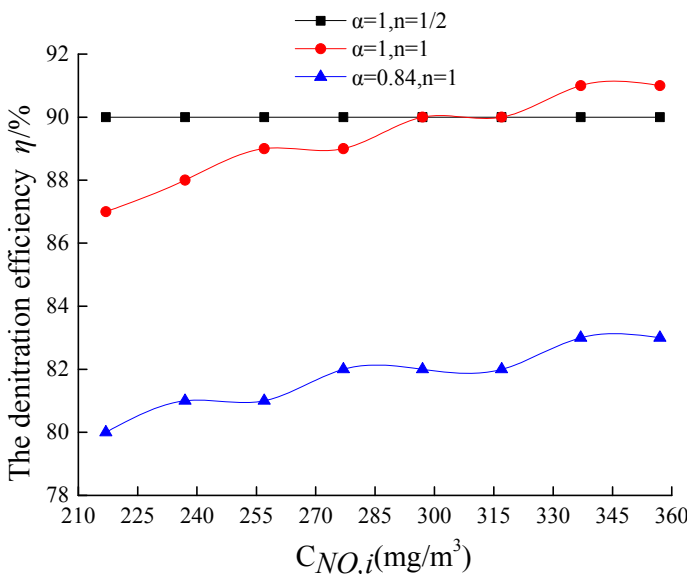

Fig.3 The effect of inlet $\mathrm{NO}_{\mathrm{X}}$ concentration distribution of the SCR reactor on denitration efficiency

\subsection{The experiment result and analysis}

The performance experiments on SCR denitration system have been done under the high load$600 \mathrm{MW} \&$ the low load-320MW, which of the results as shown in fig. 4 and fig. 5.

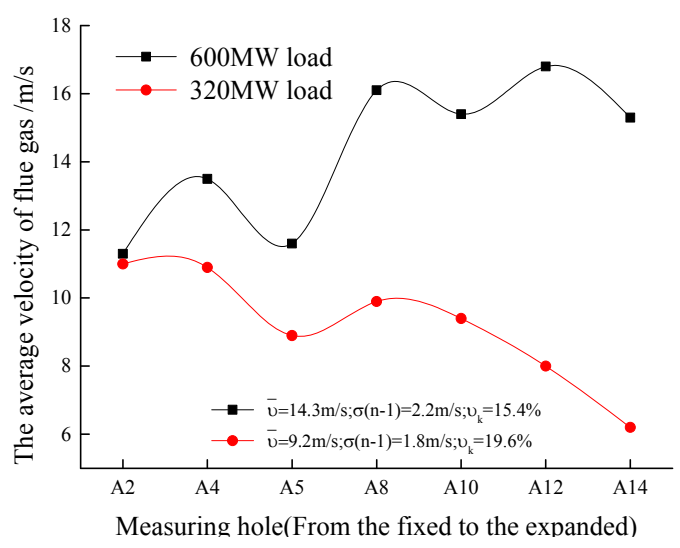

Fig.4 The inlet velocity distribution of SCR reactor

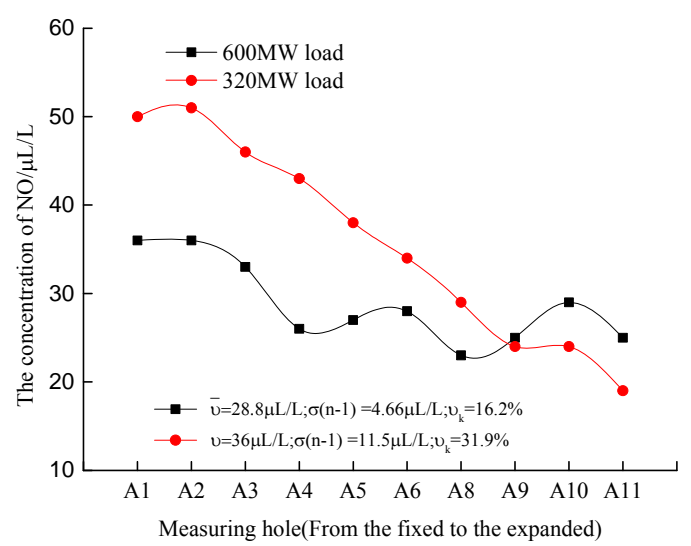

Fig.5 The SCR reactor outlet $\mathrm{NO}_{\mathrm{X}}$ concentration distribution under the 320MW load

Fig. 4 shows the entrance velocity distribution at the SCR reactor of A side, it can be seen flue gas velocity distribution under the working condition of 
$600 \mathrm{MW}$ is relatively uniform in general, other from the measuring point A2, A4, A5 that the flue gas measurement speed slightly low. But under 320 mw load, the relative standard deviation vk of flow field velocity at SCR inlet is $19.6 \%$ (over engineering allowed on the speed of the standard deviation coefficient of $15 \%$ ), which increased by $4.2 \%$ compared with under the working condition of 600 MW. That is to say, the boiler working load form $600 \mathrm{MW}$ to $320 \mathrm{MW}$, the uniformity of flow field distribution at inlet becomes poor, and there is an opposite trend on distribution of the flue gas flow between 600MW and 320MW.

Without the situation of the ammonia injection changed, velocity distribution must have effect on $\alpha$ value and even denitration effect of different parts of reactor, which also influence the distribution of $\mathrm{NOx}$ concentration at the reactor outlet.

Fig.5 shows the NOx concentration distribution at SCR reactor outlet under above loads, where the reactor $\mathrm{NO} x$ concentrations were $59.0 \mathrm{mg} / \mathrm{m}^{3}$ and 73.8 $\mathrm{mg} / \mathrm{m}^{3}$, which still can satisfy the $\mathrm{NOx}$ emission standards in our country, but the $\mathrm{NOx}$ distribution at outlet is uneven, compared with fig.4 and Fig.5, it can be seen that NOx distribution homogeneity at denitration reactor outlet with the load change is different, which the relative standard deviation vk is $31.9(600 \mathrm{MW})$ and $16.2 \%$ respectively. Compared to the unit under $600 \mathrm{MW}$ Load, the denitration outlet NOx relative standard deviation $v \mathrm{k}$ is bigger under $320 \mathrm{MW}$ load, increased by $96.9 \%$, which could not meet the requirement of relative standard deviation $v \mathrm{k} \leqq 20 \%$, showing the distribution of flow field at SCR inlet under $320 \mathrm{MW}$ load changed a lot then the $600 \mathrm{MW}$, resulting the opposite trend between two loads

As shown in Fig.5,Fom the average velocity of flue gas at reactor outlet, it can be seen that flue gas flow at SCR inlet under $600 \mathrm{MW}$ load is 1.5 times more than $320 \mathrm{MW}$ load, so the reaction time $\tau$ under $320 \mathrm{mw}$ load is 1.5 times more than 600 MW load. According to the related boiler efficiency of SCR catalyst temperature curve, the denitration efficiency under $320 \mathrm{MW}\left(310{ }^{\circ} \mathrm{C}\right.$ as corresponding temperature at SCR inlet) is $96 \%$ under the $600 \mathrm{MW}\left(355^{\circ} \mathrm{C}\right.$ as corresponding temp-erature),

Which can be thought that value $\mathrm{k}$ of the reaction (6) under $320 \mathrm{MW}$ is $96 \%$ under the $600 \mathrm{MW}$, so reaction (14) of $\mathrm{k} \tau$ value is 1.4 times than that of 600 MW. Considering the ammonia nitrogen raitio $\alpha=0.8$ samely, and 300 MWload inlet $\mathrm{NOx}$ concen-tration is higher than $600 \mathrm{MW}$, which could be concluded that the denitration efficiency $\eta$ under low load should be higher.

However, according to the results of the field experiment, the denitrification efficiency is $78.3 \%$ under $320 \mathrm{MW}$ with the maximum ammonia escaping.Compared to the results through theoretical analysis, the $\eta$ measured at field test on the $320 \mathrm{MW}$ is relatively lower than that under $600 \mathrm{MW}$ when $\mathrm{NH}_{3} / \mathrm{NO}$ ratio stays constant, of which mainly lies in the obvious change of flue gas flow field at SCR inlet, distributing in an opposite trend to that under $600 \mathrm{MW}$. Improvement and optimization of rectifying device at denitrification inlet flue is recommended to realize uniform flow field, thus in addition to the improvement of NOx distribution uniformity at denitrification outlet and reduction of ammonia escaping rate, the denitrification efficiency is increased, hopefully achieving the SCR denitrification system with a style in economic operation.

As restricted by power plant operation, this paper only studies operation of the boiler under two kinds of load (high load (600 MW) and low load (320 $\mathrm{MW})$ ), Due to the large difference range for working load between $600 \mathrm{MW}$ and $300 \mathrm{MW}$, considering the denitration performance experiment would be carried out in the midst of a load, which to further study the influence of boiler load change on the denitration system research.

\section{CONCLUSIONS AND RECOMMENDATIONS}

This paper studies boiler working load have effect on SCR denitration system through the denitration performance experiment under different loads based on the SCR device in $600 \mathrm{MW}$ unit at one power plant, the main conclusions and recommendations are as follows:

(1) Compared to the NOx distribution at SCR outlet under the 600MW, the 300MW's has become more uneven with the relative standard deviation vk being quite large.

(2) According to the integral equation of the reaction rate of $\mathrm{NO}$ concentration in A reactor, When the values of $k \tau$ and ammonia nitrogen ratio $\alpha$ are definite value, the higher the NO concentration at reactor inlet is, the higher the denitration efficiency is. However, both in the pilot experiment and field experiment, the measured denitration efficiency increases with the NO concentration falling, which could be due to the high NO concentration, and NO contact with the surface of the catalyst opportunity is limited, causing part NO molecules could not react with $\mathrm{NH}_{3}$ on the catalyst and escape directly.

(3) Compared to the results through theoretical analysis, the denitrification efficiency measured at field test on the $320 \mathrm{MW}$ is relatively lower than that under $600 \mathrm{MW}$ when $\mathrm{NH} 3 / \mathrm{NO}$ ratio stays constant, the reason of which mainly lies in the obvious change of flue gas flow field at SCR inlet, distributing in an opposite trend to that under $600 \mathrm{MW}$.

(4) Improvement and optimization of rectifying device at denitrification inlet flue is recommended to realize uniform flow field, thus in addition to the improvement of $\mathrm{NO} x$ distribution uniformity at denitrification outlet and reduction of ammonia escaping 
rate, the denitrification efficiency is increased, hopefully providing guidance on the economical operation of SCR denitrification system.

\section{REFERENCES}

Fang Z.J., Jin L.P., Yu M.L. 2015. Research on Optimization adjustment for ammonia injection and operation of SCR denitrification system in coal-fired power plant [J]. Electric Power Technology and Environmental Protection31(6):3942.

Gu W.R., Zhou M.J., Ma W. et al. 2012. Research progress on selective catalytic reduction De-NOx catalysts[J]. Chemical Industry \& Engineering Progress31(7): 1493 -1500.

Li D.B., Liao Y.J., Xu Q.S., et al. 2014. Field operation optimization for SCR denitration system of boiler in power station[J].Guangdong electric power 27(5):16-19.

Liang C., Shen Y. 2012. Optimal operation of selective catalytic reduction(SCR) flue gas denitrification system in 1000 MW unit[J]. Electric Power45(1):41-44.

Ma S.Z., Jin X., SUN Y.X., et al. 2010. Generation mechanism and control of ammonium sulfate in SCR flue gas denitrification process [J].Thermal power generation 39(8):12-16.

Qin S., Zhang J., Tian L.Y. 2012. The controling measures of nitrogen oxides in thermal power plants[J]. Energy Environmental Protection26(4):44-47.

Wang G.L., Zhang Y., Wang S., et al. 2015. Operation optimization of selective catalytic reduction system based on support vector machine[J].Chinese Journal of Environ-mental Engineering9(10):5011-5016.

Yang J.G., Fan L.A., Zhao H., Mou W.B., et al. 2014. Improving the coordination and optimization of the smoke temperature in the catalyst reaction efficiency [J]. Chinese Journal of Electrical Engineering34(14): 2245-2250. 